\title{
Small scale fisheries in Europe: A comparative analysis based on a selection of case studies
}

\author{
O. Guyader ${ }^{a, *}$, P. Berthou ${ }^{b}$, C. Koutsikopoulos ${ }^{c}$, F. Alban $^{d}$, S. Demanèche ${ }^{b}$, M.B. Gaspar ${ }^{e}$, \\ R. Eschbaum, , E. Fahy ${ }^{g}$, O. Tully ${ }^{h}$, L. Reynal', O. Curtil ${ }^{d}$, K. Frangoudes $^{d}$, F. Maynou
}

\author{
a Ifremer, UMR AMURE, Unité d'Economie Maritime, BP70, F-29280 Plouzane, France \\ ${ }^{b}$ Ifremer, Unité Sciences et Technologies Halieutiques, BP70, F-29280 Plouzane, France \\ ${ }^{c}$ University of Patras, Department of Biology, 26504 Patras, Greece \\ d Université de Brest, UEB, UMR AMURE, 12 rue du Kergoat, CS 93837, 29238 Brest Cedex 3, France \\ e National Institute of Biological Resources, INRB/L-IPIMAR, Av. 5 de Outubro, s/n, 8700-305 Olhão, Portugal \\ ${ }^{f}$ Estonian Marine Institute, University of Tartu, Vanemuise 46, 51014 Tartu, Estonia \\ ${ }^{g}$ Fisheries Ecosystem Advisory Services, Marine Institute, Rinville, Oranmore, Co. Galway, Ireland \\ ${ }^{\mathrm{h}}$ Ifremer, Unité Biodiversité et environnement, Pointe Fort, 972 Le Robert, Martinique \\ ' Institut de Ciències del Mar (ICM-CSIC), Psg. Marítim de la Barceloneta 37-49, 08003 Barcelona, Spain
}

\author{
*: Corresponding author: O. Guyader, Tel.: +33298224393 ; fax: +33298224776 ; \\ email address : oguyader@ifremer.fr
}

\begin{abstract}
:
Small-scale fisheries have traditionally received less research effort than large-scale fisheries and are generally under-studied in Europe. In spite of their comparatively low volume of catches and economic importance, small-scale fisheries are socially important and an integral part of the European coastal zone. Considering the high heterogeneity of situations and the paucity of quantitative data, we used an analytical methodology based on the comparative method. We carried out an analysis of small-scale fisheries (SSFs) in Europe based on a selection of nine case studies. Our objective was to obtain a comprehensive description of small-scale fleets covering different areas/fisheries/species, encompassing the diversity and specific conditions under which SSFs operate, in order to demonstrate the ecological and social sustainability of this often overlooked fisheries segment. A common approach formulated so that the case studies could be compared with the case histories of other competing users, required that for each set of criteria - technical, biological, socio-economic, and institutional - a set of relevant items and indicators was established. An analysis of characteristics common to the selected case studies is conducted and an attempt made to extend our comparisons to the whole of the European Union. Our results show that (as compared with large-scale fleets, their main competitor) small-scale fleets: (i) are composed of smaller vessels and, consequently, travel lower distances to fishing grounds, and are more reliant on coastal areas; (ii) have smaller crews (although the global employment figure is similar to that of large-scale fleets in Europe); (iii) use mostly, but not exclusively, passive gears; (iv) use multi-purpose fishing approaches, and can change the fish species they target during the year; (v) have lower extraction rates; (vi) have lower total capital investments (including fishing rights), turnover and costs; and (vii) have lower fuel consumption, making them less sensitive to changing oil prices. Dependence on subsidies is lower (viii). Involvement in fisheries management is variable, conservation and access regulation measures are largely local in origin. For the selected case studies, the most significant competitors are large-scale fleets, and recreational fisheries, but other sources of interaction (water quality, invasive species, etc.) cannot be ignored.
\end{abstract}

Keywords: Small-scale fisheries ; Common fisheries policy ; Fleet ; Indicators ; Fishing rights 


\section{Introduction}

The main requirement for the sustainable development of fisheries is the present and future well-being of the bio-ecological system, the human system and the management process (Garcia et al., 2008). Knowledge on these aspects for SSFs in Europe is generally limited (Symes and Phillipson, 2001; Battaglia et al., 2010), even though the SSF are strongly represented in all European Union member states. Conventional fisheries assessment systems, developed for large-scale fisheries, do not provide an adequate basis for the management of SSFs because they assume a relatively simplistic relationship between the productive capacity of the resource and the extractive capacity of fishing fleets (Garcia et al. 2008). A management scheme based on reference points such as Maximum Sustainable yield, has little meaning when the necessary information on fleet structure, fish abundance, fishing mortality and regulation are missing. The need to improve our knowledge about SSFs in order to secure their sustainable development is increasingly recognized (FAO, 1995; Chuenpagdee et al. 2006; Salas et al., 2007; Chuenpagdee Ed. 2011). Combining enhanced information on SSFs and the use of a comparative approach is a useful step forward in analysing the current circumstances - technical, biological, socio-economic and institutional - conditioning this activity with regard to its immediate competitors for space or the resource. Combining such assessments with an effective advisory process should help improve the outlook for a type of fishery that is especially vulnerable to globalization, modernization and increasing pressure on resources (Garcia et al., 2008).

SSFs have been generally neglected in Europe by fisheries scientists and management at national and supranational levels. This neglect arises from an underestimation and under-appreciation of the social and economic value of the contribution of SSFs to societal well-being (Garcia et al., 2008). Although SSFs are often ignored or marginalized because of their comparatively low economic value (Guyader et al., 2007a), they are important in terms of employment, and may be locally important in economic terms. They reinforce the attachment people feel for their territory, enhancing social stability in rural and peripheral areas.

Taking an overall vessel length of $12 \mathrm{~m}$ as a practical delimitation between small-scale and large-scale fisheries in Europe (EC, 2006), ca. 70,000 (or 84\%) of the 25 member states' fleets in the European Union can be considered as SSF, providing direct employment for ca. 100,000 people (Guyader et al., 2007a). SSFs are present all around European coasts, and have local socio-economic importance in peripheral and ultra-peripheral regions. The high number of fishing vessels involved in SSF and the distribution of this fleet along an extended coastline make the monitoring of the SSF fleet segment extremely complex (Lleonart and Maynou, 2003).

Despite the lack of knowledge about their structure and functioning, their social importance and specificity are often recognised in terms of employment or with regard to their supposedly limited impact on resources, but these references are made usually in generic terms (EC 2001), probably because the exact delimitation of SSFs is neither easy nor necessary. Johnson (2006) identified two dimensions to fisheries: the social organization of production, and the spatio-temporal dimension of operations, contrasting small-scale and large-scale fisheries. Based on this scheme, SSFs in Europe are composed of relatively small fishing groups with a low level of division of labour, and fish products are mostly destined for local sale. In addition to small size, the vessels are owner-operated and require relatively low capital investment as 
compared to large-scale vessels. Small-scale fishing vessels use a wide variety of fishing techniques to target a wide array of seasonally changing resources, although their overall catch is generally low. This relatively low catch has, however, a high unit value and the product is often destined for tourist markets or local markets with high purchasing power in the EU. Fishing is conducted relatively near to shore and fishing operations last usually one day or less (a radius of operation within $12 \mathrm{~nm}$ of home port is often added to the definition of SSFs). Due to an assumption that they have a relatively low economic impact and volume of catches, SSFs are not regularly monitored by national or local administrations.

The main problem regarding the management of SSFs is that the complexity of the sector and the lack of systematic studies lead to the formulation of assumptions, rather than the presentation of the intangible elements that define the sector's profile at EU level. An evaluation of the assumptions concerning the nature and role of the SSF is of crucial importance for the management of these fishing activities, especially if they require special treatment for the purpose of establishing management plans (Campbell and Pardede 2006; Defeo et al. 2005).

Given the pressures on the fishing industry today at European level, for example the over-exploitation of fish stocks, overcapacity of fleets, energy dependency, and market globalization (EC, 2009), SSF may, in actual fact, be in a strategically favourable position in the future compared to other sectors of the industry. The requirement to develop environmentally friendly fishing methods favours the use of static fishing gears, these being the predominant gears used by European SSF. The fact of adding value to fresh products of good quality and their differentiation on the market - within the context of a fiercely competitive international trade with imports to the EU on the increase - may also give these fleets a competitive advantage. Fishing costs, especially fuel cost per unit of production, may also be lower in SSF using passive gears. SSF may also be favourably situated in terms of regional planning or, equally, at an advantage in view of the fact that they maintain a primary activity in coastal zones all along the year. As the mobility of SSF is assumed to be limited, and the exploited resources are confined in many cases to within 12 nautical miles of the home port, SSF management could be implemented in a context of maritime spatial planning. At present, SSF conform both to national regulations within the provisions set out under the Common Fisheries Policy (CFP) for vessels in the $0-12 \mathrm{~m}$ overall length segment, and to CFP regulations on fleet capacities and technical measures. To date, SSF have not been identified as a special case, and in policy terms have largely been ignored by Europe and sometimes by the member states. The vacuum in policy may have left SSF exposed to the race for fish" and so to competition from within the sector, and also to pressures from other sectors such as large-scale fleets, recreational fishing, tourism, aquaculture, and other users of the coastal zone and activities carried out on land. An evaluation of SSF specificities (EC green paper 2009) examining their strengths and weaknesses, the general context for the preservation of fish resources and ecosystems, and economic and social components has already drawn attention to the need for a specific framework for the management of the SSF.

The aim of this paper is to analyse the status of European SSFs based on a selection of case studies, following a comparative approach of selected indicators. This analysis explores several important dimensions: technical, biological, socio-economic and institutional, and studies conflicts arising from interactions with other competitors: large-scale fleets, but also recreational fisheries, aquaculture, aggregate removal or wind farms, coastal development, ecosystem conservation, etc. 


\section{Approach framework and methodology}

The methodological framework relies on the principle that a comparative approach to the SSF will reveal useful elements about the main common features characterising all, or at least the vast majority, of these fisheries. The use of the comparative approach has been suggested by Garcia et al. (2008) in the framework of an Integrated Assessment and Advisory process advocated for SSFs. Nine case studies covering a large range of gears and métiers ${ }^{1}$ were selected in order to get a better picture of the diversity and specific conditions under which SSF are operating. The selection of the case studies was mainly governed by the availability of data. As required by the European Commission in the call for tenders for the study of SSFs in Europe, the selected fleets should operate in the Baltic Sea (Estonia), the Atlantic Ocean (Ireland: 2 cases, France: 2 cases, Portugal) and the Mediterranean Sea (France, Greece). One case study is from an overseas tropical area (ultra-peripheral region of Martinique, France) (see Figure 1).

Case 1 is the Estonian fixed pound net fleet targeting Baltic herring and garpike in the Gulf of Riga, the second case being the Mediterranean net and line fleet targeting hake and other species in the gulf of Patraikos (Greece). The other Mediterranean case study concerns the gillnetters from Corsica island (France) harvesting finfish and spiny lobster. The dredge fleet of Algarve (Portugal) target different shellfish species (Case 4). The fifth and sixth case studies relate to activities in the Iroise sea in Brittany (France), the hook and line fleet catching mainly sea bass and pollack, and the kelp harvest dredgers operating on seaweed and scallops. The two Irish case studies are located on the Southern and Northwest part of the country, the first being whelk potters, the second being crab potters (case 7 and 8). Case 9 is a fleet of hook and line vessels operating on moored fish aggregating devices (FAD's) off Martinique in the southern Caribbean.

\footnotetext{
${ }^{1}$ A métier is a group of fishing operations targeting a similar (assemblage of) species, using similar gear, during the same period of the year and/or within the same area and which are characterised by a similar exploitation pattern" (European Commission Decision 2010/93/EU, Appendix I Chapter 1, p.9). Identification of different metiers is however not always straightforward in practice (Deporte et al. 2012).
} 
Figure 1 - Selected SSF case studies in Europe

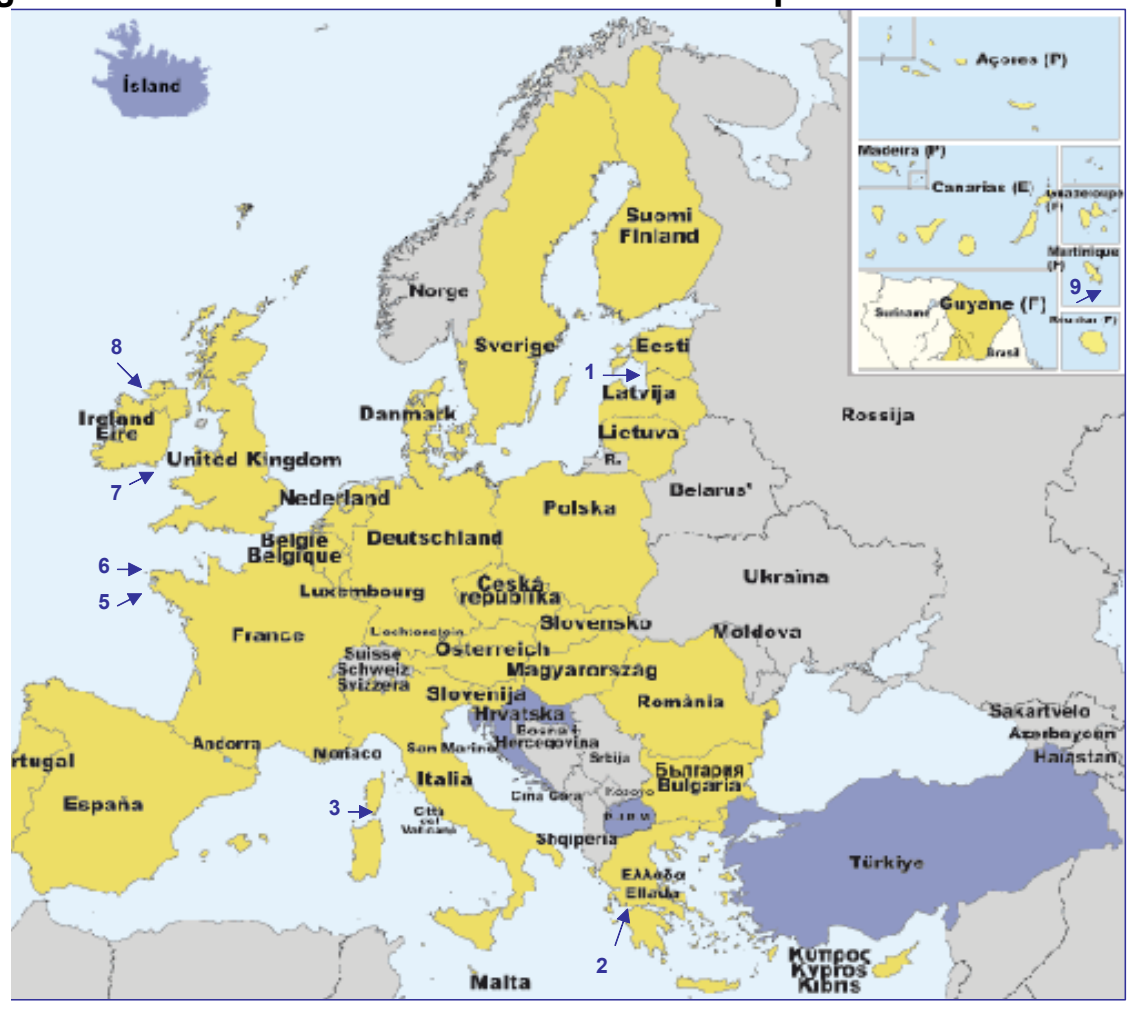

1. Herring and garpike pound net fleet in Gulf of Riga (Estonia)

2. Finfish net and line fleet of the Mesolonghi lagoon and gulf of Patraikos (Greece)

3. Spiny lobster and finfish net fleet in Southern Corsica (France)

4. Bivalves dredge fleet of the Algarve coast (Portugal)

5. Finfish hook and line fleet of the Iroise Sea (France)

6. Seaweed and bivalves dredgers of the Iroise Sea (France)

7. Whelk pot fleet of the South West Irish Sea (Ireland)

8. Crab and lobster trap fleet of the North coast (Ireland)

9. Pelagic hook and line fleet of Martinica (French West Indies)

Source : European Commission

As far as possible, comparisons of the results obtained from the selected SSF with the results from a selection of Large-scale fisheries (LSF) operating within the same country or in the same fisheries were carried out. The dividing line demarcating SSF from LSF is of a conventional nature, and was set at a vessel length of $12 m(E C, 2006)$ in order to test the differences. For each case study we collated information from different national databases and reports (see Guyader et al. 2007 for more details), and compiled the data in a SSF_matrix_indicators file. Additional data were taken from the Community Fleet Register (http://ec.europa.eu/fisheries/fleet/index.cfm) and from the results of the report on the economic performance of selected European fishing fleets (Anon., 2005).

The comparative criteria cover technical, biological, socio-economic and institutional issues in order to explore the different dimensions under which SSF operate. Specifically, we analyzed the technical characteristics of the vessels, labour, gears used, fishing grounds, effort (in terms of activity), degree of specialization, value of production, prices and markets, productivity, costs, competition for resources and 
species, impact on stocks, management levels (local, regional, national, supranational) and regulations.

A set of assumptions was tested to examine the dependency of SSF on coastal areas and resources. The issue of competition for resources and space (with other fleets and with other marine activities) was assessed, as well as their relative impact on the stocks and the environment. We examined whether SSFs differ from their main competitor, LSFs, in terms of organizational structure (ownership, employment, invested capital, ...), fleet structure, gears used or safety, but also in terms of product valorisation and income. As the level of information per case study was heterogeneous, a minimum common matrix set including the same indicators for all segments was defined, as well as an extended common matrix set applicable to a more limited number of case studies.

In order to ensure the homogeneity and the comparability of indicators between the case studies, the scale and the units of measure were standardized across the case studies. Data sets provide indicators for all individual units within the segment, or for sub-samples at segment level, or at an aggregated level for competitors. The data available is quantitative or qualitative. In the latter case, the data were processed to provide semi-quantitative indicators. In conformity with OECD (2000), a rating system for each indicator was established in order to calculate the indices of performance. Semi-quantitative indicators were then used to assess the performance of the SSF according to a given set of criteria. The matrix of interactions between SSF and competitors is also described qualitatively or semi-quantitatively with respect to the intensity and impact of the interaction with SSF.

\section{Results and Discussion}

\subsection{Structure of segments and trends}

Case studies concern sample populations varying between approximately 37 and 441 fishing units (Table 1). Five case studies $(1,2,6,7,8)$ out of nine in total have seen a downward trend in the number of vessels over the last ten years, with a relatively large drop for case 8 . The numbers of boats making up individual fishing units remained stable over ten years in three of the case studies $(3,4,5)$, and in just one case (9), the fleet has undergone a period of expansion linked to the development of the fishing activity to include pelagic species (Guyader et al., 2007a). The global trend for these case studies is on average downward, and this confirms more general developments in numbers of vessels in each EU member state (Cueff, 2007). Decommissioning schemes have partly contributed to this evolution, although there had been no intention at the outset to reduce numbers in view of capacity adjustment objectives for some segments (see Guyader et al., 2007b for the French case). None of these fisheries are managed by ITQs. 
Table 1. Vessel characteristics

\begin{tabular}{|l|c|c|c|c|c|}
\hline \multicolumn{1}{|c|}{ Case Study } & Nb Vessels & Aver. Length & $\begin{array}{c}\text { Aver. Engine } \\
\text { power (kW) }\end{array}$ & $\begin{array}{c}\text { Aver. } \\
\text { Tonnage (GT) }\end{array}$ & Aver. Crew \\
\hline 1. EST-Gulf-Riga-pound net & 74 & 9.6 & 31 & 4.3 & 2.7 \\
\hline 2. GRC-Patraikos-net and line & 441 & 6.8 & 17 & 1.8 & 1.8 \\
\hline 3. FRA-Corsica-netters & 39 & 8.0 & 85 & 3.5 & 1.3 \\
\hline 4. PRT-Algarve-dredgers & 52 & 8.9 & 54 & 6.4 & 2.8 \\
\hline 5. FRA-Iroise-Sea-hook and line & 37 & 8.0 & 104 & 4.0 & 1.1 \\
\hline 6. FRA-Iroise-Sea-kelp harvest and dredgers & 42 & 9.8 & 77 & 10.4 & 1.5 \\
\hline 7. IRL-Irish-Sea-whelk potters & 65 & 11.5 & 87 & 14.9 & 2.8 \\
\hline 8. IRL-North-West-Ireland-crab potters & 148 & 8.1 & 34 & 4.6 & 1.5 \\
\hline 9. FRA-Martinique-hook and line on FADs & 91 & 7.2 & 109 & 2.5 & 2.0 \\
\hline
\end{tabular}

The vessels in our case studies, with average length, power, and tonnage of $8.6 \mathrm{~m}, 66$ $\mathrm{kW}$ and $6 \mathrm{GT}$ respectively, have mean technical characteristics that clearly distinguish them from LSF $(21 \mathrm{~m}, 325 \mathrm{~kW}, 114 \mathrm{GT}$ respectively) but that are slightly higher than average for units less than $12 \mathrm{~m}$ in length in the countries concerned $(7.1 \mathrm{~m}, 42 \mathrm{~kW}, 2.8$ GT). In many case studies, differences between the declared and effective technical characteristics have been identified - and notably those relating to engine power (kW) without it being possible to quantify them, but the problem is not confined to SSF. Although the case studies have close average sizes in common - between $7 \mathrm{~m}$ and $10 \mathrm{~m}$ (with the exception of case 7 ) and an average vessel length of $8.6 \mathrm{~m}$ for the case studies - the other technical characteristics of power and tonnage are more heterogeneous and it is difficult to establish systematic relationships between these variables. Differences in vessel characteristics are mainly explained by their fishing activities; gears and equipment used or areas of operation.

The overall average fleet age in the case studies is 20 years. The most recently built fleet was the Martinique Fishing Aggregation Devices (FADs) fleet that is still expanding (8.7 years old, case 9), while the oldest fleet is the relict whelk fleet in the South West Irish Sea (27.5 years old, case 7), the Algarve dredge fleet and Corsica netters (cases 3 and 4 ) being very similar. If all the fleets in the countries examined are considered, it is clear that there are few differences in average age between SSF and LSF fleets. However, discrepancies are found between fleets from different countries or regions. In many cases (across the range of case studies) the average fleet age was 25 years. The exceptions to this rule concerned fleets of French boats operating in the Atlantic and in Martinique, and Estonian vessels of less than $12 \mathrm{~m}$. This situation can be shown to be a direct result of EU fleet management policy implemented in Member States, which has led to a reduction in fleet sizes, and cut-backs in ship building (Cueff, 2007; Lindebø, 2005). As described below, the arrival of new units in the fishing fleets is, in almost all case studies, dependent on obtaining an operation permit or licence with a numerus clausus. SSF fishing fleets do not, therefore, appear to be an exception to this rule.

\subsection{Crew}

Most SSF case studies have on average fewer than three persons per boat, and the average of all case studies is 2.0 compared to 5.3 for LSF. It is believed that numbers of crew employed during fishing operations have been reliably reported to us, and it is also the case that these figures do not necessarily agree with officially reported crew employment. Higher numbers of crew are often the result of a more labour intensive fishing operation (cases 1 and 4) or a larger size of vessel which, in order to be 
economically sustainable, must carry a larger crew to handle a greater quantity of gear (case 7). It is not possible to define a homogeneous crew education level between case studies since the situations concerned are very different. Social insurance and retirement systems vary between Member States, but all cover the main risks sickness, work accidents, and old age - to varying degrees.

\subsection{Gears used, dependency on coastal areas and external competitors}

Six of the nine segments studied used only passive gears (cases $1,2,3,5,7,8$ ) while in cases 6 and 9, vessels employed both passive and mobile gears. Case 4 is the only case where boats used only mobile gear. At the European level, the main and secondary gears declared in the Community Fleet Register indicate that the use of passive gears is a strong feature of small-scale vessels for all European countries. SSF are mainly operating with passive gears, but active gears cannot be ignored because they are exploited by the larger and more powerful SSF vessels. Vessels under $12 \mathrm{~m}$ in length have a higher degree of polyvalence in terms of their ability to use several kinds of gears, and to switch from one to another in order to target different species during the year, than larger, more mobile, vessels.

Table 2. Characteristics of the case studies

\begin{tabular}{|l|c|c|l|c|}
\hline \multicolumn{1}{|c|}{ Case Study } & $\begin{array}{c}\text { Type of gears } \\
\text { used }\end{array}$ & $\begin{array}{c}\text { Dependance to } \\
\mathbf{1 2} \mathbf{~ n m} \text { area }\end{array}$ & $\begin{array}{c}\text { Type of fishing } \\
\text { ressources }\end{array}$ & $\begin{array}{c}\text { External } \\
\text { competitors }\end{array}$ \\
\hline 1. EST-Gulf-Riga-pound net & Passive & $100 \%$ & Sedentary & Yes (LSF) \\
\hline 2. GRC-Patraikos-net and line & Passive & $100 \%$ & Sedentary, Migratory & Yes (LSF) \\
\hline 3. FRA-Corsica-netters & Passive & $100 \%$ & Sedentary & Yes (RF, LSF) \\
\hline 4. PRT-Algarve-dredgers & Mobile & $100 \%$ & Sedentary & Yes (RF) \\
\hline 5. FRA-Iroise-Sea-hook and line & Passive & $100 \%$ & Sedentary, Migratory & Yes (LSF, RF) \\
\hline 6. FRA-Iroise-Sea-kelp harvest and dredgers & Mobile & $100 \%$ & Sedentary & No \\
\hline 7. IRL-Irish-Sea-whelk potters & Passive & $100 \%$ & Sedentary & No \\
\hline 8. IRL-North-West-Ireland-crab potters & Passive & $100 \%$ & Sedentary, Migratory & Yes (LSF) \\
\hline 9. FRA-Martinique-hook and line on FADs & Mobile/Passive & $38 \%$ & Migratory, Sedentary & Yes (LSF, RF) \\
\hline
\end{tabular}

Note: LSF (large scale fleets), RF (Recreational or informal fleets)

A key issue was to assess vessels' global range of operation, and especially the degree of dependence of the SSF on coastal areas. Analysis of the case studies shows that fleets in 8 out of the 9 case studies only exploit coastal areas (Table 2). Even though small vessels in this study generally undertake coastal fishing within the $12 \mathrm{~nm}$ limit, some fishing activity can remain very coastal (within $3 \mathrm{~nm}$ ), while other fleets may develop their activity further out to sea for part or all of the year. The only exception concerns the fleet operating on FADs in Martinique lying beyond the $12 \mathrm{~nm}$ limit. SSF vessels, being of small size, can only operate in general within a relatively small range of the coastline. Small size often confines their activities to limited and hospitable areas; often they are able to only exploit a stock during one brief phase of its life cycle: they may be unable to pursue a target in waters outside the area in which their size allows them to perform. The analysis of the degree of dependence of national fleets confirms the strong dependence of $<12 \mathrm{~m}$ vessels on the territorial and coastal waters zone. However, Guyader et al. (2007a) underlined that vessels of $12-15 \mathrm{~m}$ are also highly dependent on this zone, and vessels $15-30 \mathrm{~m}$ in length also exploit fish in this area. The coastal zone is not only exploited by small-sized commercial vessels but 
also by recreational fishers resulting, in many cases, in high exploitation pressure on the stocks and/or areas that are exploited by SSF.

\subsection{Organizational structure of fishing units and invested capital}

The structure of vessel ownership was considered at two levels: the organizational structure of fishing units (ranging from self-employed single operators to individual fishing companies) on the one hand, and fleet level on the other, by examining indicators on the concentration of the vessels in the hands of a single owner. Most vessels are operated by owner-skippers. Also, most vessels are privately owned and most owners have only one vessel (6.5\% own more than one vessel). Generally, where owners possess more than one vessel, it is because a second vessel is a technical requirement for the type of fishing concerned, rather than being an indication of any ambition to invest or capitalize into the sector. However this is not the case in case study 4 , where it is common for an owner to have more than one vessel. A large proportion of owners come from traditional fishing families and the vast majority are in continuous contact with the sea and the locality of their base ports. Investment by nonrelated enterprises in the selected case studies appears to be absent.

Capital investment was estimated to assess whether investment in SSF is lower than the average investment in fisheries generally, and if the impact investment has on employment in SSF is greater than that on employment in LSF in the same country. We can distinguish between two routes to access the fishing sector: buying a new vessel, or purchasing an active unit on the second-hand market. Whatever the indicator used, there is high variability in the construction costs for units belonging to the SSF selected. The price per unit length may vary, for example, by as much as $100 \%$. The price of fishing units rises with the length of the vessel, but other elements of the technical characteristics of the boats and their equipment (engine type, fishing gears, etc.) necessary to the fishing operations can influence the price of the vessels. In these case studies there is, therefore, a fairly high variability in construction prices that can be explained by these elements, but also by the probable differences in construction costs in the different countries concerned.

A fisher's investment is not necessarily limited to the capital investment in vessel and equipment, but must also extend to SSF access rights or privileges. MRAG et al. (2009) and OCDE (2006) have shown that there is wide variation in access regulation modes between member states, and between fisheries within member states. Fishing rights can take the form of licences, territory rights, and/or individual quotas. Whether fleets are small or large-scale, entry to the fishing industry depends on having a Community fishing licence. Taking the value of fishing rights into consideration seems to be important for most of the fleets studied, especially those subject to access regulation. The cost of these rights represents, depending on the case study, between $26 \%$ and $50 \%$ of the value of the investment, but this proportion can reach higher values when old, low value vessels are purchased (Guyader et al. 2006). These rights are directly exchanged explicitly on a so-called market (cases 1, 2, 3) or exchanged implicitly through the sale of the vessels to which rights are attached on the second hand market for vessels (cases $4,5,6$ ). This finding is confirmed by MRAG et al. (2009), which demonstrates the increasing importance of the use of fishing rights in Europe and the existence of implicit markets for these rights. The access to these rights or privileges could constitute - and is often seen as - a barrier to entering the sector, but it is precisely one of the objectives of these regulations to restrict access, and to reduce incentives to enter the fisheries sector. 
It is quite difficult to compare the value of the capital invested on the European scale, both because of the diversity of the variables measured, and the heterogeneity of the indicators used, but the relative investment is higher for units over $12 \mathrm{~m}$ long as compared to those under 12m long (IREPA, 2006). This is another calculation often encountered when reasoning in terms of vessel costs. In terms of capital intensity, indicating the value of the capital invested per crewmember, the same results are found. For the French Atlantic fleet, the invested capital per crew member is $20 \mathrm{k} € 40$ $k €$ and $60 \mathrm{k} €$ for the $<7 \mathrm{~m}, 7-9 \mathrm{~m}, 9-12 \mathrm{~m}$ vessels respectively, and reached $120 \mathrm{k} €$ for the $12-24 \mathrm{~m}$ vessels. Whether in terms of total capital value or total capital necessary for one fisher to work, investment in the SSF is generally more limited than in the LSF.

While it was not possible to provide a comprehensive overview of the current availability of financial resources available for new and second-hand vessel purchase, a selection of the financial packages that would, at some time, have been applicable for some of the fleets concerned was analyzed. For cases 5 and 6 average finance rates cover the period 1981-2001. Subsidies account for $10 \%$ of resourcing, and financial investment in the form of loans is of the order of $70 \%$. In the case of the French Atlantic fleet a large part of the subsidies allocated were to boats of over $12 \mathrm{~m}$ due to the rising rate of subsidies according to the length of vessels and the price of vessels. Even this case cannot be generalized, as the rate of self-financing increases with decreasing vessel size.

\subsection{Level of activity and safety risks}

Average SSF activity expressed in terms of days at sea is 150 days per annum compared to 190 days for LSF (Figure 2). Various explanations are available for these differences. Some segments are constrained by the behaviour of fish stocks, inshore fisheries management regulations, and also by meteorological conditions. In some cases, the time consecrated to the sale of landings, or gear maintenance requirements limit activity at sea. SSF vessels are not intentionally part-time operators even if some fishers do develop other non-fishing activities. Activities other than fishing mainly concern the primary and the secondary sector, agriculture, building, forestry and the service sector (restaurants, hotels). Marine tourism or passenger transport is also practised in certain cases but it is often restricted by safety regulations concerning passenger transport in the countries studied. A distinguishing characteristic of SSF is their daily activity pattern; those harvesting fish usually do so in the morning, returning in the afternoon to sell their landings fresh. Daily fishing trips also require vessels to work in close proximity to their base port. Overall average steaming time in these case studies is between $25 \%$ and $30 \%$ of time at sea moving to and from fishing locations and between locations. Fishing trips on average last $8 \mathrm{~h}$, and this allows SSF operators to pursue a more family-friendly life style than crew in LSF. 
Figure 2. Vessel activity in days at sea for SSF and LSF

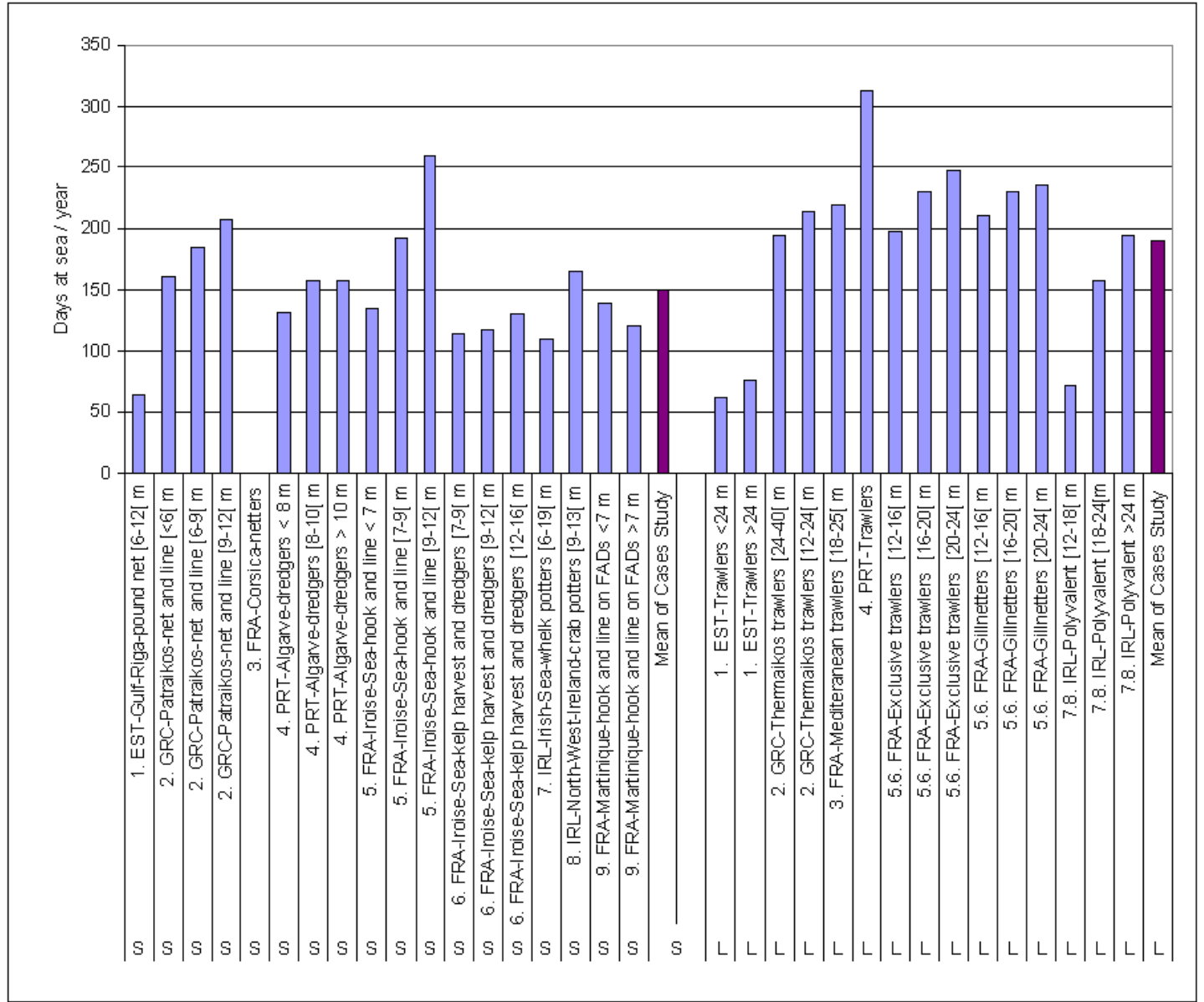

Note: S (Small scale fleets) L(Large scale fleets).

There is a dearth of information on the question of whether SSF are more exposed to safety risks than LSF. Even when statistical data can be found, it is considered that a higher proportion of work-related injuries in SSF are misreported compared to LSF. It is important to emphasise that SSF are more exposed to adverse weather conditions than LSF, increasing the risk of crew injury. On-board living conditions in SSF are more exposed, and vessel safety features may be inadequate in many situations. The small number of crew on smaller vessels is conducive to the risk of accident especially when there is only one fisher on board. Moreover, multiple use of an area for fishing and other activities such as aquaculture, wind farms and recreation also raises the risk of collision in inshore areas. Fisheries regulations have an impact on the working conditions of the vessels and crews but this is not specific to SSF (Megapesca, 2000; Kaplan and Kite-Powell, 2000).

\subsection{Dependency on species, landings and marketing conditions}

The analysis of dependency on species was carried out by identifying the number of species generating $70 \%$ of the revenue of the fleets. The SSF selected are, on average, dependent on a fairly limited number of species. This number is 3 on average taking all vessels in the case studies into account, with a minimum of 1 species for cases 1,5 and 7 and a maximum of 8 species for case 2 using net and line in the 
Mediterranean (Tzanatos et al. 2005; 2006). The average for all the LSF is higher, with 6 species generating $70 \%$ of the turnover. It is considered that species dependency results from the gears used and their selectivity, and on the ecosystem in which they are operated. Species diversity increases from North to South, and some gears, in particular trawls, are generally less selective than passive gears. Even if the exploitation is based on a more limited number of species, it is however difficult to decide about the sensitivity of the SSF to variations in abundance of the resources. Some fleets can be extremely dependent on these species, whereas others, due to the polyvalence of their activity, are able to re-allocate their fishing effort towards other targeted species over short time scales.

There is great variability in the total volume landed by the SSF studied and this situation can be explained both by the size of the segments studied and, as mentioned above, by the heterogeneity of individual landings between case studies (Guyader et al. 2007a, p. 393). Over all case studies, the average turnover per exploitation unit is around $€ 61 \mathrm{~K}$, while it is $€ 356 \mathrm{~K}$ for the LSF that mobilize larger means of production (capital and work) and develop a greater activity at sea. Finally, the average price of fish for SSF is $€ 4.10$ per $\mathrm{kg}$, compared with €2.80 per $\mathrm{kg}$ for the LSF. For SSF and LSF landing the same species, SSF generally improve production value to a higher degree than the LSF, and the gap between prices at first sale can be very high (Figure 3).

Figure 3. Prices at first sale for SSCF and LSF for the same targeted species

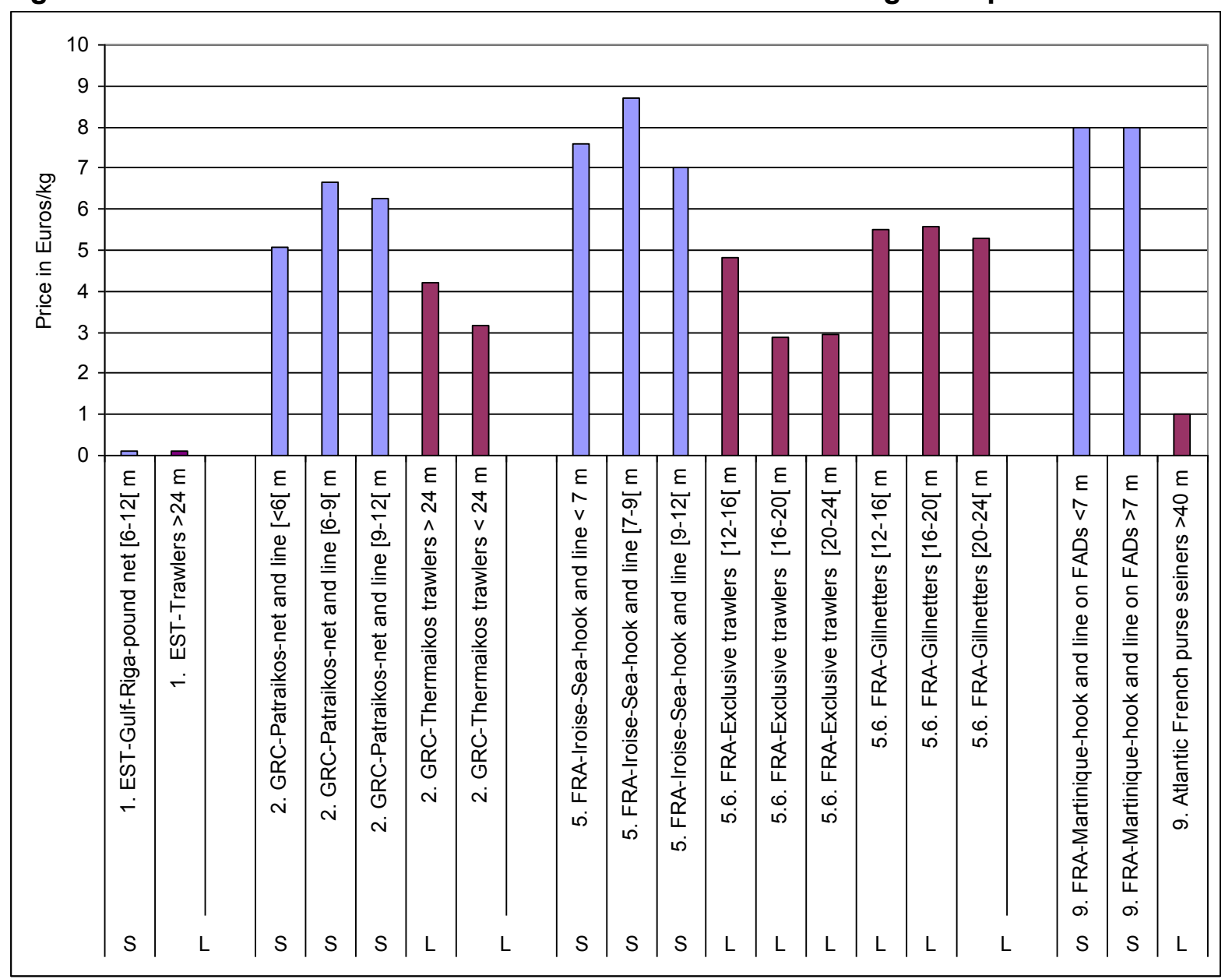

Note: S (Small scale fleets) $L($ Large scale fleets). 
These gaps may be explained by both the differences in quality (linked to freshness) and size of the products. SSF fish are usually intact, while trawled fish may be damaged, and there is also the impact of a longer trip duration in the case of the latter, due to the type of marketing channels used, but there is also a degree of degradation linked to the time taken to identify the products (case 5). The relatively low quantities landed by most SSF also allow the crew to devote more time to preparing and selling the landings. In some cases however, the small size of the vessels limits onboard handling and storage facilities or the absence of appropriate infrastructure in the ports may reduce the quality of the product.

With the exceptions of case studies 6 and 8 , all other fisheries are somehow dependent on local and regional markets and only a few products are sold at national level. It is also interesting to note the high dependence of some of the case study fleets on the international market (Alban et al. 2004). For instance, products in case 7 (whelk) are exported to Asia and those in case 4 (clams) are mainly exported live to Spain. However, in these two fisheries a proportion of the product is also sold for local and regional consumption. Conversely, in case 6, the fishery is exclusively dependent on the international seaweed market.

In the vast majority of cases, however, SSFs do not take advantage of the EU withdrawal price system (see DGMARE 2008 for a description of the system). No ecolabelling mechanism has been identified in the selected case studies. However, the marketing of products is in some cases organized according to a system of labelling which makes it possible to identify the product on the market (case 5). The system contributes added value thus securing a better return to fishers (Charles et al. 2003). It was noted, however, that in some cases the large volume of LSF landings arriving on the market may seasonally have a significant impact on the price of the products also landed by the SSF (see also competitors).

\subsection{Productivity, socio-economic returns and employment in SSF}

From the analysis of our case studies it appears that landings per crewmember are lower in the case of SSF than LSF. It follows that the harvest per crewmember is lower in the case of SSF. This is naturally true for the cases where the different activities are targeting the same stocks. These elements suggest fundamental differences in the economic characteristics of jobs in SSF and LSF and these aspects are further discussed elsewhere. It has been seen previously that the volume and value of the scales of production vary widely from one SSF to another, and also between SSF and LSF. Simple productivity of capital - with engine power used as a proxy of capital - is on average higher for LSF compared with SSF. The same conclusions are reached regarding simple productivity of labour. One job at sea generates, on average, for this study, a €33K turnover in SSF compared to €67K for LSF. It is also true for the landings in volume per crewmember when SSF and LSF target similar and comparable species. If the rate of use of the means to production is taken into account, and the calculation expressed in terms of daily production and working hours and capital investment, the differences in average are reduced or even reversed.

Based on the case studies, daily average capital investment returns are identical between SSF and LSF ( $€ 6$ per kW per day) and the indicator of hourly productivity is higher for SSF ( $€ 0.9$ as compared to $€ 0.6$ per kW per hour). However, these indicators are influenced by the nominal engine power of the boats, so it is preferable to use the capital value in calculating the indicator rather than its physical proxy،. The indicators 
of daily production and working hours are more homogenous between case studies. While daily productivity is, on average, higher for LSF than SSF, hourly productivity calculated on a more limited sample shows higher average results for SSF.

It is also commonly assumed that fuel consumption by SSF is lower than fuel consumption by LSF, because SSF mostly operate with passive gears and spend less time at sea (Tyedmers et al., 2005; Van Marlen Ed., 2009). Annual fuel consumption varies according to each of the case studies, but the average was about 15,000 l/yr per vessel. For the LSF, the figure for this average is ten times higher at 150,000 litres per year. This consumption in volume or value was also related to other variables such as activity at sea, engine power or even turnover. Related to activity expressed in days at sea, consumption was less than $100 \mathrm{l} /$ day for SSF and more than $700 \mathrm{l} /$ day for LSF. The indicator of fuel cost as a proportion of turnover gives a good indication of the economic dependency of fleets on fuel consumption (Figure 4 ). The average for SSF is $9 \%$ of turnover and $18 \%$ for LSF, making the former less sensitive to fuel price increase. Different elements can explain this difference but one of the reasons is the structure of the segments studied. LSF are mainly composed of boats using towed gears, and these can be very fuel-consuming, while SSF are mostly boats using fixed gears. However, some fleets in SSF (Case 4, 5 and 9) use mobile fishing techniques with higher costs in fuel per euro of catch than those of French large-scale netters operating in the Atlantic. It is also possible that some boats simply have better fish to fuel consumption ratios. Finally, some differences can be attributed to the different fuel charges in the member states and even within a state. In general, diesel oil is purchased for use in fisheries at a lower cost than on the open market. This system is common to all the case studies, and is probably widespread throughout the EU. It is also noted that the selected fleets operating from islands (cases 3 and 9) pay a higher fuel price than those operating from continental zones.

Figure 4. Fuel cost as percentage of gross revenue for SSCF and LSF

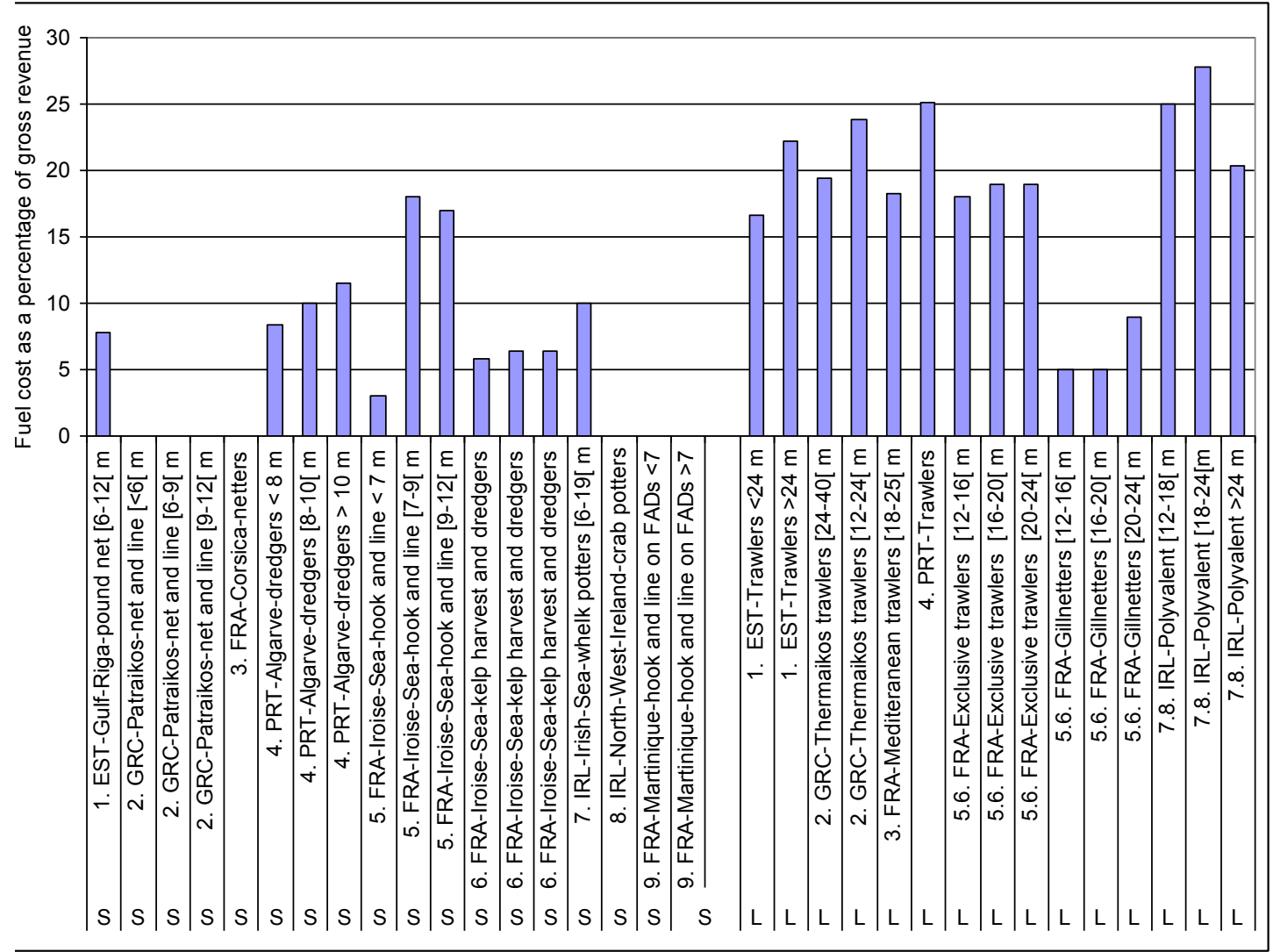

Note: S (Small scale fleets) L(Large scale fleets). 
Only 4 case studies out of 9 yielded data for characterizing the economic status of the SSF studied. The economic assessment of the SSF also poses a certain number of difficulties. Indeed, on the one hand, some firms pursue a multi-purpose approach to their fishing activity, and the complementary income generated by these activities is not often available to undertake analyses of their global economic performance. Then, on the other hand, the distinction between remuneration of work and remuneration of the invested capital is not systematic for many units, especially for those in which the owner is also the fisher on board (Boncoeur et al., 2000). For the whole set of case studies, the crews were paid according to the principle of the share system, which is a profit sharing scheme so crew members' earnings in effect relate to the company's performance. The mean wage paid to the fishers in each case study was compared with alternative types of remuneration in the rest of the economy assessed either via the minimum national wage or the average national wage.

As a precursor to what follows, we note that the appropriateness of using these indicators as a cost of opportunity (the value of the best alternative) of the work mobilized in the fishing activity is open to question, because there is disparity, not just in the educational levels of the fishers involved, but also in the job opportunities that exist for what is in effect a relatively immobile population in the zones where the fishing activity is carried out. Notwithstanding, using these indicators as a working basis, "wages» in the SSF are higher in three cases out of four than the minimum or average wage. When the comparison is made in terms of total income, the difference is positive over the whole set of cases. These results are consistent with the fact that in 4 of the 9 case studies reported, the fishing access rights involved have a significant value on the market, i.e. the expected value of fishing compared to opportunity cost is positive. In several cases however, the survival of SSF seems to be mainly rooted in limited diversification possibilities, and this is true in numerous areas throughout Europe.

The issue of a fishery's attractiveness can also be approached by examining the age structure of fishers. The average age is quite high (46 years) but it is difficult to distinguish SSF from LSF. In the same way as the numbers joining LSF are currently in decline, SSF may well be experiencing a reduction in recruits, but this is difficult to quantify.

The high number of SSF units within the $25 \mathrm{EU}$ member states suggests that total employment in these fleets can be significant. Although it was not possible to accurately estimate the total for all EU fleets, some rough estimates from the case studies and the Community Fleet Register reveal as many crew in vessels $<12 \mathrm{~m}$ $(100,000)$ as in larger vessels. The total number of jobs in the fishing industry at EU level is 200,000 (Anon, 2005). All the above-mentioned elements show clearly that the contribution of SSF to direct employment is an important one. A certain number of studies have sought to assess the spillover effects in terms of spin-off and indirect jobs in the fishing activity in Europe but they rarely enable the SSF to be distinguished from the LSF (Goulding, 2000). Adding to this the fact that SSF operate throughout Europe and frequently in areas with low employment opportunities (rural areas, isolated islands, for instance), the social benefits of viable SSF may be high.

The involvement of women in the domain of fishing activities proper is minor in the case studies selected. The participation rate ranges from $0-4 \%$ for 8 of the 9 documented cases. LEI (2006) reported $4 \%$ of female fishers where the information on the employee's gender was available. It was also noted that a higher proportion of women are involved in aquaculture harvesting in France, Spain and Portugal, but are not included in the number of fishers (LEI, 2006). The last report on the current 
situation of employment in the fisheries sector confirmed that there are very few women employed in marine fishing. The involvement of women in other vital functions in fishery exploitation, concerning mostly the selling of fish, and bookkeeping, is by no means insignificant. Women represent between $13 \%$ and $20 \%$ of the workforce in cases 2,5 and 6 , and up to $90 \%$ in case study 3 . In case studies 7 and 8 , the wives of fishers are more involved in sea product processing activities that do not necessarily have a direct link with SSF exploitation.

\subsection{Competition for the resource and space, with other fleets and with other marine activities}

For the SSF case studies, the most significant external competitors, when such were identified, are LSF, both from the point of view of access to stocks and fishing zones and also in terms of market supply and domination. Various types of interactions with potential competitors were considered for the case studies. Each case study was awarded a rating of 0 (no interaction), 1 (low interaction), 2 (medium level of interaction) and 3 (high interaction) (see figures 5 and 6). The second and third principal sources of interaction with SSF are recreational fishers and illegal fishers, respectively, who put pressure not only on resources but also on access to fishing zones in a number of cases. The recreational fishing sector has increased markedly in recent years, overlapping with the small-scale fisheries in terms of space and resource use, and having a significant impact on coastal resources (Morales-Nin et al., 2005, 2007; Cardona et al., 2007). On the other hand, illegal fishing (especially in cases 7 and 9) also distorts the fish products market, as their sales compete with the sale of legal fishers' landings, and the latter are subject to higher production costs due to taxation, social contributions and compliance with licensing and other regulations.

Figure 5. Level of competition for access to stocks

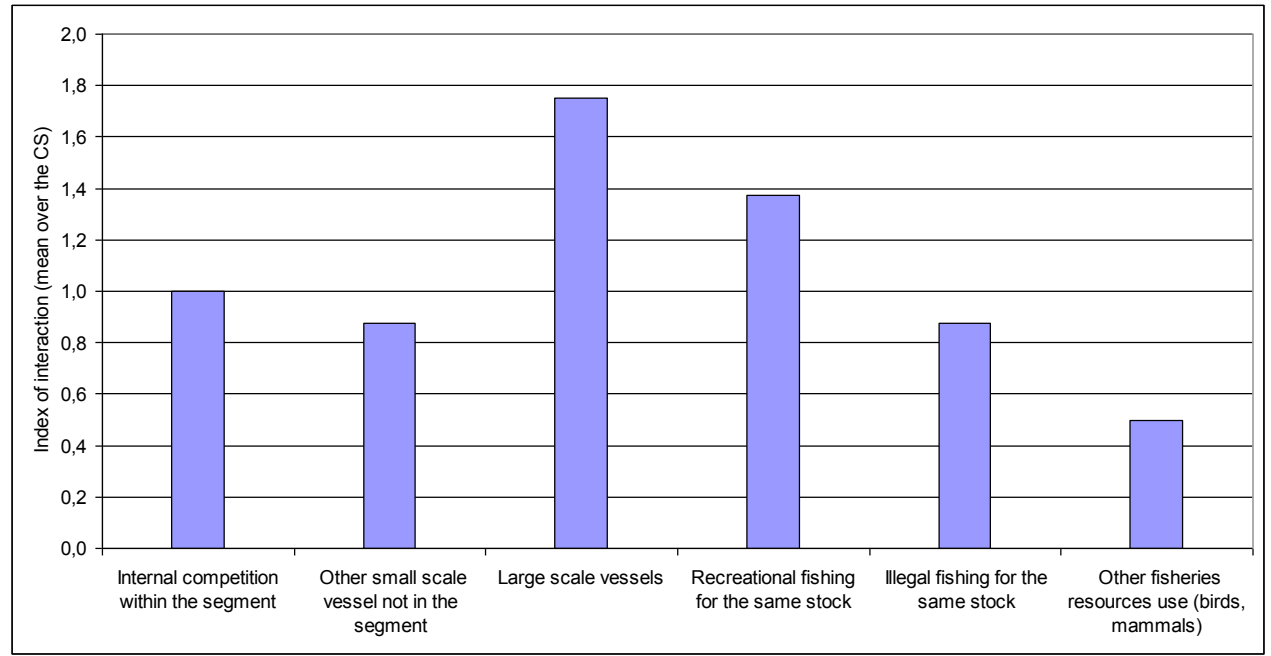

* Average level between case studies

Note. (3) High level of competition, 2 (Medium level), 1 (Low level), 0 (No competition) 
Figure 6. Level of competition for access to fishing grounds

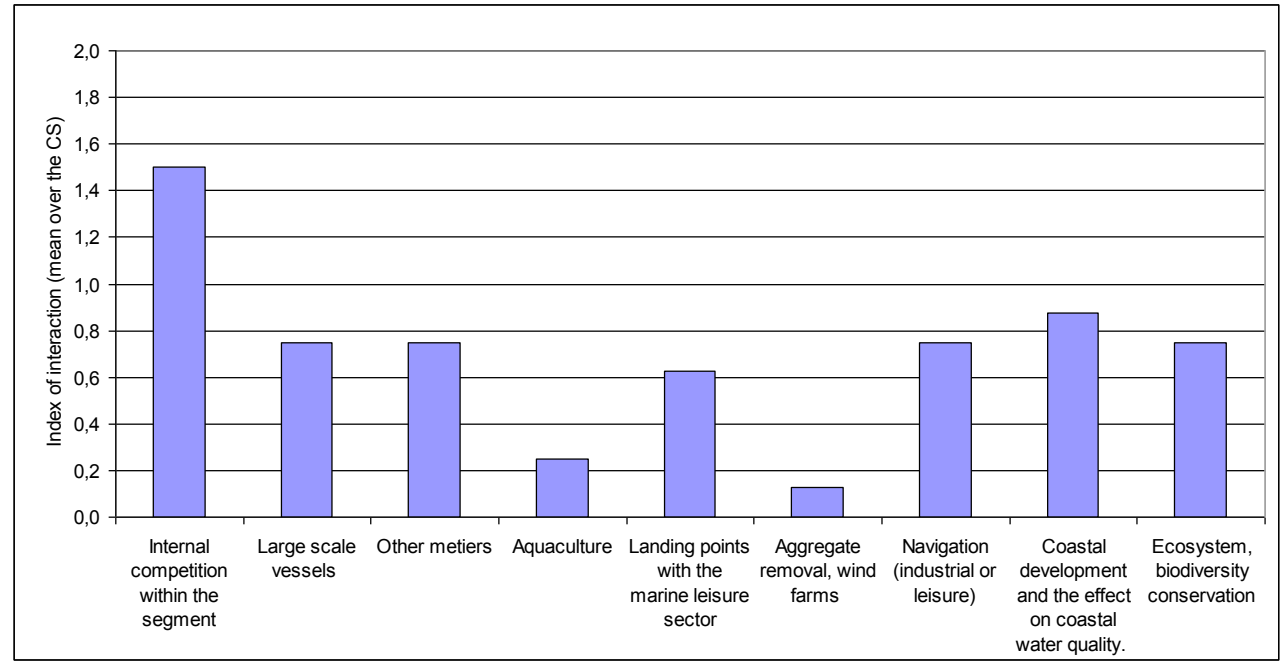

* Average level between case studies

Note. (3) High level of competition, 2 (Medium level), 1 (Low level), 0 (No competition)

There was less information on competition arising as a result of the economic development of coastal zones, probably owing to the case studies selected. Problems anticipated relate to water quality, invasive species and to the spatial occupation of the littoral and coastal zones (navigation and aquaculture conflicts). Coastal zones are also the focus for protection measures for ecosystems and the environment in general, and these are the source of increasing constraints on the occupation of coastal space. Site designations subject to the Habitats and Birds Directives have a significant constraining effect on SSF in some cases. One important point is that in most cases the economic value of SSF is considerably lower than many competing activities in the coastal zone. This is likely to result in increased pressure on SSF, with negative consequences for their future. However, SSF are an integral part of the socioeconomic fabric and their significance is underestimated by considering only their production value.

\subsection{Impacts on stocks}

LSF has received most of the attention given to fisheries management issues and fish stocks assessment (Lleonart, 2008). The result is a lack of knowledge about what makes the SSF effective and sustainable compared to the LSF. The inconsistency of the available data is an obstacle to testing the assumption that SSF has less impact than LSF on fish stocks. In 3 of the 9 case histories there is no comparable LSF, in 4 of the 9 there is no other SSF with which to make comparison, and in 3 of the case studies there are no recreational fisheries. These circumstances suggest that in many instances SSF may be the only fishery exploiting a particular niche resource. Where comparison is feasible, the species and size range composition have to be taken into consideration. Unfortunately such an exercise often requires a carefully planned and standardized approach. According to case studies, the analysis suggests that SSF are less harmful to stocks than LSF exploiting the same species, due to the relatively less productive fishing technologies they usually employ. However, in cases of resources confined to specific ecosystems accessible to SSF, they undoubtedly have the potential to create overcapacity due to internal competition, and to over-exploit local fisheries. 
3.10. Involvement of SSF in fisheries management at local, regional, national, and EU level

As illustrated in the case studies comparison, the level of involvement by fishers" representatives is relatively homogeneous among case studies, with the exception of cases 2 and 6 (Table 3). The relatively high participation indices in 6 of the 8 documented cases may be explained mainly by high levels of participation in local and regional decision-making. Overall however, participation in national institutions is average or weak, except in the Greek case study, and almost non-existent at EU level.

Table 3. Index of involvement in fisheries management at different decisionmaking levels

\begin{tabular}{|l|c|c|c|c|}
\hline \multicolumn{1}{|c|}{ Case Study } & Local & Regional & National & EU \\
\hline 1. EST-Gulf-Riga-pound net & 3 & 3 & 2 & 0 \\
\hline 2. GRC-Patraikos-net and line & 1 & 1 & 2 & 1 \\
\hline 3. FRA-Corsica-netters & 3 & 3 & 1 & 1 \\
\hline 4. PRT-Algarve-dredgers & 3 & 3 & 1 & 0 \\
\hline 5. FRA-Iroise-Sea-hook and line & 3 & 3 & 1 & 0 \\
\hline 6. FRA-Iroise-Sea-kelp harvest and dredgers & 1 & 0 & 0 & 1 \\
\hline 7. IRL-Irish-Sea-whelk potters & 2 & 2 & 1 & 1 \\
\hline 8. IRL-North-West-Ireland-crab potters & 2 & 2 & 1 & 0 \\
\hline 9. FRA-Martinique-hook and line on FADs & 3 & 3 & 1 & 0 \\
\hline Average case studies & 2.3 & 2.2 & 1.1 & 0.4 \\
\hline
\end{tabular}

Note. (3) High level of participation, 2 (Medium level), 1 (Low level), 0 (No participation)

Processed from stakeholders knowledge and literature review

In some case studies, participation by SSF in management is actively facilitated by state agencies and the result is positive, especially in case studies 4, 5, 6 and 8 . Even if they are not referenced in this study, self-management situations can also be observed, as is the case for the Mediterranean prudhomies and cofradias (Dufour, 1996; Franquesa, 2004). According to the case studies, participatory co-management seems to be more successful when there is greater economic dependency on SSF by the participants. If the fishery is under SSF control and there is little outside competition then the results of participation in management can have direct and positive effects on management measures and legislation (see for example Gutierrez et al., 2011)

It is useful to explore some of the reasons explaining declining participation, moving from local through national to European level. In many cases fishers are linked to specific ecosystems and resources, and the task of understanding and managing these is usually compatible with administrative and management structures at local or, at highest, regional level. The diversity of the sector, the opportunity cost of being involved in management systems and poor information flow between the SSF and higher administrative levels can have the effect of discouraging active involvement by fishers. Bottom-up decision-taking structures are more accessible and friendly to SSF than centralised top-down systems (Jentoft, 1989). The structure of management 
systems and the capacity to cope with the heterogeneity and size of SSF are also factors that preclude a higher level of involvement on the part of regional or national administrations in the management of SSF. At a higher administrative level, SSFs are regarded as very diverse, and little is known about them individually by managers. This problem is shared at international level (McGoodwin, 1990).

\subsection{Fisheries regulation in SSF}

Two broad categories of fisheries management measures have been distinguished in practice - conservation measures, and access regulation measures (Garcia and Boncoeur, 2005; Boncoeur et al., 2006) - and studied at different scales (EU, National, regional or local). The purpose of conservation measures is to preserve the capacity of fish stocks to grow and to renew themselves. In fisheries biology terminology, this involves controlling both production per recruit, and the relation between spawning stock biomass and average long-term recruitment. Although much less systematically developed, a second and complementary set of measures is aimed at explicitly resolving the problems concerning the common pool nature of marine fish stocks. Once limitations have been put in place to ensure acceptable levels of harvesting via conservation measures, the aim of access regulation is to set up mechanisms that limit the negative aspects of competitive harvesting, by allocating each operator's share of the production possibilities a priori. This involves, first, identifying the operators who can participate in the fishery for a given fish stock or set of fish stocks; and second, defining each operator's share of the authorized fishing possibilities.

An analysis of the different fisheries management measures was carried out within this study. However, comparison of case studies shows that conservation measures are not solely EU decisions; they are decided in practically equal proportions at EU, national or regional/local levels. Access regulations are established at national or regional/local level, their objective being in general to restrict entry to the fishing sector. These measures are often complemented by individual fishing privileges regulating conditions of access to specific fisheries. These are licensing conditions with limitations on fishing, annual or daily fishing quotas or Territorial Use Rights in Fisheries (TURFs) giving individual fishers rights to fishing zones. These measures are largely local in origin illustrating that SSF are subject to access regulation, sometimes more than LSF. However, open access situations are possible in SSF, as is the case of the Irish Sea whelk fishery (Fahy, 2008).

The rights or privileges in force in the case studies, when they exist, do not protect SSF very effectively against their competitors. Rights are generally allocated for a long period or for an unspecified duration. Regulatory systems are in general based on fairly well-established legal systems, and the transferability of rights - whether explicit or implicit - is more or less generalized. The fact that the transferability of rights is implicit does not ensure quality of right or privilege. In particular, this may affect the fisher's expectations and the efficiency expected of a system of transferable rights. The absence of an explicit market, but not necessarily of a licence or entitlement, also means that it is extremely difficult to regulate and impose measures intended, in particular, to avoid concentration of rights among a small number of operators. Finally, rights are in many cases hard to divide up since they are generally based on vessel characteristics, which can be aggregated but which are difficult to divide into units. In some cases, however, it is possible to aggregate or disaggregate rights, especially in the context of explicit markets for fishing rights or privileges. 
It is often considered that the management of SSF can be implemented via social control imposed on the SSF by local communities. This point is not verified in the selected case studies. Local or regional fisher's organisations exist, but they have a status that leads them to implement measures within an established legal framework. Case studies were also analyzed to ascertain whether access to local resources was reserved for local stakeholders, but this did not produce a consistent answer. While true in some cases, in others no special allocation existed. The type of permit put in place by the local fisher's organization may in some cases favour the inheritance of a company by a son from his father but it is not possible to generalize on this point. SSF are mainly exploited by local fishers.

\section{Conclusions and discussion}

Although it would be presumptuous to suggest that the 9 case studies can adequately reflect all types of SSF scenario in Europe and elsewhere, this study identifies a number of factors that SSF have in common and draws some conclusions about SSF viability. These conclusions are also based on more comprehensive understanding of SSF in Europe. We first showed the strong heterogeneity of SSF both in terms of vessels' technical characteristics and gears used. While a large majority of vessels use passive gear, a significant share of more powerful vessels operates with mobile gears. The use of several different types of gear is generally more prevalent among SSF as compared to LSF, but polyvalence is not systematic within the SSF sector. This is also true when one considers the degree of dependence on species, which highlights differences in fishers' ability to adapt to changing fish stocks. Fishing activity expressed in days at sea throughout the case studies is on average relatively high, although lower than that of LSF, but what most distinguishes the SSF from LSF is their fishing grounds, with much shorter fishing trips. This aspect is a fundamental element of SSF, and is not neutral in terms of quality of life and attractiveness of the profession. One striking characteristic of SSF is the variable level of involvement: this may be full time in many cases, or part-time, whereby participants combine the activity with other economic activities in the coastal area. The fact that vessels are owner-operated is not a distinctive feature of SSF to the extent that LSF, and sometimes large numbers of them, are also operated under the same conditions.

Another key result is that harvest rate per crewmember is lower in the case of SSF and this is naturally true for the cases where the different activities are targeting the same stocks. These elements suggest fundamental differences in the economic characteristics of jobs in SSF and LSF, at least in Europe. It was shown at the outset that the SSF achieve generally higher market value for their catches, due to better product quality and shorter marketing channels. However, we showed that there is no standard marketing for SSF landings. Certain products are marketed locally or regionally in niche markets and other products are exposed to very competitive world markets. The degree of dependence on fuel is also lower for the SSF than LSF, but this is true for vessels using passive gears. This is particularly important since the vulnerability of SSF to fuel price increases is much lower than LSF. Whether in terms of total value of capital or capital necessary for one fisher to work, the investment in the SSF is generally more limited than in the LSF. The amount of subsidy allocated to LSF in the form of finance capital was proportionately higher than that allocated to SSF, but how this has been taken into account for SSF in different countries seems to have been heterogeneous. This is confirmed by Cappell et al. (2010) who assessed the impacts of the Financial Instrument for Fisheries Guidance (FIFG) from 2000 to 2006 and underlined that support to SSFs was not explicitly recognised in all Member 
States. Dependence on subsidies is lower for SSF and this is particularly crucial for the future viability of fleets considering the current subsidies ban for vessel building at EU level. It was beyond the scope of this paper to compare small-scale fishing firms to other small and medium enterprises (SME) in Europe. Most of the fishing firms can be considered as small, or micro-firms, and the impact of public policies on small businesses could be studied across a wider spectrum with a comparison between sectors (Storey 2005).

Comparison of the current economic profitability of SSF would have required more precise information, especially on the alternatives for fishers in the economy in terms of employment and wages. In selected case studies, the economic characteristics in which SSF operate reduce their relevance to local communities, but in other circumstances reliance on SSF is very high, and in these cases they play a major role both in the economy and the social structure of those areas. The SSF can play a role as a tourist attraction, in particular due to them being perceived as a traditional activity by the public. Whatever the case, SSF maintain job opportunities in the primary sector and throughout the year in coastal zones and this could prove very important in term of regional planning. SSF have the potential to be an attractive and profitable activity in coastal communities. This is sometimes hindered today by uncertainty over the future availability of stocks because of poor management or/and competition for areas in the coastal zone.

Involvement of SSF in fisheries management and implementation of conservation measures or/and access regulation is variable in the selected case studies and depends mainly on country organisation. Positive experiences exist and involve professional organizations, but situations of open access are also referenced. The rights or privileges in force in the case studies, when they exist, do not protect SSCF very effectively against their competitors. For the SSF case studies, the most significant external competitors, when such were identified, are LSF, both from the point of view of access to stocks and fishing zones. The second and third principal sources of interaction with SSF are recreational fishers and illegal fishers. There was less information on competition arising as a result of the economic development of coastal zones, probably owing to the particularity of the case studies selected. Anticipated problems relate to water quality, invasive species and to the spatial occupation of the coastal zones (windmills, aggregate extraction, navigation and aquaculture conflicts).

The reforms to the Common Fisheries Policy raise the question of taking greater account of SSF (EC, 2009). A more efficient management framework for SSCF could be developed by firstly recognizing the strengths and weaknesses of the sector, within the context of the global management of the fishing sector, and coastal zone management. The study highlighted the high dependence of SSF on coastal and territorial waters, which would justify the reinforcement of fisheries management systems that are more closely aligned with fishing rights at company or fishery level within this space to support their activities. The reduced mobility of the SSF makes them extremely dependent on local and regional ecosystem resources. It is of crucial importance to recognize this special link and incorporate it within the management principle. While access regulations are often already in operation, entry to the SSF sector should be better controlled in order to keep internal competition to a minimum. The allocation of rights or privileges should be considered on a long-term basis in order to create security and confidence for sustainable development of the sector, and to increase the attractiveness of the profession. 


\section{Acknowledgments}

The study was prepared with the financial support of the European Commission (contract FISH/2005/10). The views expressed are those of the authors and do not necessarily reflect the views of European Commission, nor do they anticipate its policy in this field. The authors would like to acknowledge the very helpful comments and suggestions of the Editor, the Associate Editor and two anonymous reviewers.

\section{References}

Alban, F., Boncoeur, J., Le Floc'h, P. 2004. The impact of economic and regulatory factors on the relative profitability of fishing boats. A case study of the seaweed harvesting fleet of Northwest Brittany (France). Aquatic Living Resources. 17, 187-193.

Anon, 2005. Economic performance of selected European fishing fleets. Annual Report 2005. EC Contract FISH/205/12. 306 p.

Battaglia, P., Romeo, T., Consoli, P., Scotti, G., Andaloro, F. 2010. Characterization of the artisanal fishery and its socio-economic aspects in the central Mediterranean Sea (Aeolian Islands, Italy). Fisheries Research. 102, 87-97.

Boncoeur, J., Coglan, L., Le Gallic, B., Pascoe, S. 2000. On the (Ir)relevance of Rates of Return Measures of Economic Performance to Small Boats. Fisheries Research. 49, 105-115.

Boncoeur, J., Guyader, O., Thebaud, O. 2006. A typology of fisheries management tools. Amure Publications. Working Papers Series ND16-2006. http://www.univbrest.fr/gdr-amure/documents/gdr-amure-D-16-2006.pdf

Campbell, S.J., Pardede, S.T. 2006. Reef fish structure and cascading effects in response to artisanal fishing pressure. Fisheries Research. 79, 75-83.

Cappell, R., Huntington, T., Macfadyen, G. 2010. FIFG 2000-2006 Shadow Evaluation. Report to the Pew Environment Group.

http://www.pewtrusts.org/uploadedFiles/wwwpewtrustsorg/Reports/Protecting_ocean_li fe/FIFG-evaluation.pdf

Cardona, L., López, D., Sales, M., de Caralt, S., Díez, I. 2007. Effects of recreational fishing on three fish species from the Posidonia oceanica meadows off Minorca (Balearic archipelago, western Mediterranean). Scientia Marina. 71(4), 811-20.

Charles, E., Boude, J.P., Murray, A., Pacquotte, P. 2003. Coastal fishing: resource's enhancement and preservation. Ocean and Coastal Management. 46, 421-437.

Chuenpagdee, R., Liguori, L., Palomares, M.D., Pauly, D. 2006. Bottom-up, global estimates of small-scale fisheries catches. Fisheries Centre Research Reports. 14(8), 112 (available at http://www.fisheries.ubc.ca/publications/).

Chuenpagdee, R. (Ed.) 2011. World Small Scale Fisheries Contemporary Visions, Eburon Academic Publishers, Delft, 400 p. 
Cueff, J.C. 2007. A case study of fishing vessel capacity management public buyout schemes: community experience through the multi-annual guidance programmes and ways forward, in Curtis, R., Squires, D. (Eds.) Fisheries Buybacks, Blackwell Publishing, London, pp. 75-80.

Defeo, O., Castilla, J.C. 2005. More than one bag for the world fishery crisis and keys for co-management successes in selected artisanal Latin American shellfisheries. Reviews in Fish Biology and Fisheries. 15, 2-283.

Deporte, N., C. Ulrich, S. Mahévas, S. Demanèche and F. Bastardie (2012). "Regional métier definition: a comparative investigation of statistical methods using a workflow applied to international otter trawl fisheries in the North Sea." ICES Journal of Marine Science: 69(2): 331-342.

Dufour, A. H. 1996. Management and practice in the small-scale inshore fisheries of the French Mediterranean. In Crean, K., Symes, D., (Eds.) Fisheries management in crisis. Blackwell Publishing, London, pp. 110-115.

DG MARE. 2008. Evaluation of the Common Organisation of the Markets in Fishery and Aquaculture Products. Executive summary.

http://ec.europa.eu/fisheries/documentation/studies/study_evaluation_market/

European Commission. 2001. Green Paper on the Future of the Common Fisheries Policy. European Commission, Brussels.

European Commission. 2006. Council Regulation (EC) No 1198/2006 of 27 July 2006 on the European Fisheries Fund.

European Commission. 2009. Green Paper-Reform of the Common Fisheries Policy. $\operatorname{COM}(2009) 163$ final.

Fahy, E. 2008. Performance of an inshore fishery in the absence of regulatory enforcement. Marine Policy. 32(6), 1037-1042.

FAO. 1995. Code of conduct for responsible fisheries. ftp://ftp.fao.org/docrep/fao/005/v9878e/v9878e00.pdf

Franquesa, R. 2004. Fishermen guilds in Spain (Cofradias): Economic role and structural changes, in proceedings of the XIlth biennal IIFET conference, Tokyo, Japan.

Garcia, S.M., Boncoeur, J. 2005. Allocation and Conservation of Ocean Fishery Resources: Connecting Rights and Responsibilities, in Swan, J., Gréboval, D. (Eds.) Overcoming factors of unsustainability and overexploitation in fisheries: selected papers on issues and approaches, FAO Fisheries Report $n^{\circ} 782$, FAO Rome, pp. 2348.

Garcia, S.M., Allison, E.H., Andrew, N., Béné, C., Bianchi, G., De Graaf, G., Kalikoski, D., Mahon, R.L., Orensanz, L. 2008. Towards integrated assessment and advice in small-scale fisheries: principles and processes. FAO Fisheries and Aquaculture Technical Paper No. 515. 
Goulding, I., Hallam, D., Harison-Mayfield, L., Mackenzie-Hill, V., Silva, H. 2000. Regional Socio-economical studies on employment and the level of dependency on Fishing. Lot No. 23: Coordination and consolidation study. Megapesca and Centre for Agricultural Strategy UK.

Gutierrez, N.L., Hilborn, R., Defeo, O. 2011. Leadership, social capital and incentives promote successful fisheries. Nature. 470:386-9.

Guyader, O. Berthou, P., Daurès, F., Jézéquel, M., Thébaud, O., 2006. Marché des navires d'occasion et coût d'accès à la ressource, Publication Amure, Série documents de travail D-17-2006. ISSN 1951-641X http://www.univ-brest.fr/gdramure/index2.php?affich=rap\&type=Document

Guyader, O., Berthou, P., Koustikopoulos, C., Alban, F., Demaneche, S., Gaspar, M., Eschbaum, R., Fahy, E., Tully, O., Reynal, L., Albert, A. 2007a. Small-Scale Coastal Fisheries in Europe, Final report of the contract No FISH/2005/10, http://ec.europa.eu/fisheries/publications/studies_reports_en.htm

Guyader, O., Berthou, P., Daurès, F. 2007b. Decommissioning schemes and capacity adjustment: A preliminary analysis if the French experience, in Curtis, R., Squires, D. (Eds.) in Curtis, R., Squires, D. (Eds.) Fisheries Buybacks, Blackwell Publishing, London, pp. 105-132.

Irepa Onlus. (Ed.) 2006. Evaluation of the capital value, investments and capital costs in the fisheries sector, Report No FISH/2005/03, 203 p., http://stecf.jrc.it/meetings/sgeca/0603/capital.pdf

Jentoft, S. 1989. Fisheries co-management: Delegating government responsibility to fishermen's organizations. Marine Policy. 13, 137-154.

Johnson, D.S. 2006. Category, narrative, and value in the governance of small-scale fisheries. Marine Policy. 30, 747-756.

Kaplan, I.M., Kite-Powell, H.L. 2000. Safety at sea and fisheries management: fishermen's attitudes and the need for co-management. Marine Policy. 24(6), 493-497.

Lindebø, E. 2005. Role of Subsidies in EU Fleet Capacity Management. Marine Resource Economics. 20, 445-466.

LEI. (Ed.). 2006. Employment in the fisheries sector: current situation. Project report. FISH/2004/4. 185 p. (http://ec.europa.eu/fisheries/publications/studies_reports_fr.htm)

Lleonart, J., Maynou, F. 2003. Fish stock assessment in the Mediterranean: state of the art. Scientia Marina. 67, 37-49.

Lleonart, J. 2008. Review of the state of Mediterranean and Black sea fishery resources. In: Basurco, B. (ed.) The Mediterranean fisheries sector, Options Méditerranéennes, Série B Études et Recherches" N62: 57-70.

McGoodwin JR. 1990. Crisis in the world's fisheries. People, problems and policies. Stanford, California: Stanford University Press. 
MegaPesca (Coord.) 2000. Regional Socio-economic Studies on Employment and the Level of Dependency on Fishing, Final Report, Commission of the European Communities, Directorate-General for Fisheries. (http://ec.europa.eu/fisheries/publications/studies/regional/finalreport.pdf)

Morales-Nin, B., Moranta, J., Garcia, C., Tugores, M.P., Grau, A.M., Riera, F., Cerda, M. 2005. The recreational fishery off Mallorca Island (western Mediterranean): some implications for coastal resource management. ICES Journal of Marine Science. 62, 727-39.

Morales-Nin, B., Moranta, J., García, C., Tugores, P., Grau, A.M. 2007. Evaluation of the importance of the recreational fisheries on a Mediterranean Island. American Fisheries Society Symposium. 49, 587-92.

MRAG., IFM., CEFAS., AZTI Tecnalia \& PolEM. 2009. An analysis of existing Rights Based Management (RBM) instruments in Member States and on setting up best practices in the EU. Final Report. London: MRAG Ltd. 117 p. (http://ec.europa.eu/fisheries/cfp/governance/consultations/consultation_260207_en.ht $\mathrm{m})$

OECD. 2000. Transition to Responsible Fisheries: Economic and Policy Implications, OECD publications, Paris, France.

Organization for Economic Co-Operation and Development. 2006. Using market mechanisms to manage fisheries OECD, Paris.

Salas, S., Chuenpagdee, R., Seijo, J.C., Charles, A. 2007. Challenges in the assessment and management of small-scale fisheries in Latin America and the Caribbean. Fisheries Research. 87, 5-16.

Symes, D., Phillipson, J. (Eds.) 2001. Inshore fisheries management. Reviews: Methods and Technologies in Fish Biology and Fisheries, Kluwer Academic Publishers, 2: $318 \mathrm{pp}$.

Storey D. J. 2005. Entrepreneurship, Small and Medium Sized Enterprises and Public Policies, Handbook of Entrepreneurship Research, International Handbook Series on Entrepreneurship. 1, 473-511

Tyedmers, P.H., Watson, R., Pauly, D. 2005. Fueling Global Fishing Fleets. Ambio. 34(8), 635-638.

Tzanatos, E., Dimitriou, E., Katselis, G., Georgiadis, M., Koutsikopoulos, C. 2005. Composition, temporal dynamics and regional characteristics of small-scale fisheries in Greece. Fisheries Research. 73(1-2), 147-158.

Tzanatos, E., Dimitriou, E., Papaharisis, L., Roussi, A., Somarakis, S., Koutsikopoulos, C. 2006. Principal socio-economic characteristics of the Greek small-scale coastal fishermen. Ocean and Coastal Management. 49(7-8), 511-527.

Van Marlen, B. (Ed.). 2009. Energy Saving in Fisheries, Report number C002/08FISH/2006/17LOT3.

http://ec.europa.eu/fisheries/publications/studies/energy_saving_en.pdf 